Jurnal Tabarru' : Islamic Banking and Finance

Volume 2 Nomor 1, Mei 2019

p-ISSN 2621-6833

e-ISSN 2621-7465

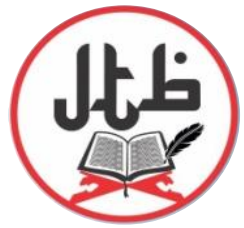

\title{
ANALISIS PERBEDAAN PEMBIAYAAN MURABAHAH BANK SYARIAH MANDIRI DAN BMT "X" DI PEKANBARU
}

\author{
Hamdi Agustin ${ }^{1}$ \& Hastri Febria ${ }^{2}$ \\ ${ }^{1} \& 2$ Fakultas Ekonomi (FE), Universitas Islam Riau (UIR) \\ Email:hamdiagustin@eco.uir.ac.id
}

\begin{abstract}
ABSTRAK
Tujuan penelitian ini adalah untuk menginvestigasi perbedaan sistem pembiayaan murabahah pada Bank Syariah Mandiri dengan BMT "X" Cabang Pekanbaru. Adapun menjadi sampel pada penelitian ini adalah Bank Syariah Mandiri dan BMT " $X$ " Cabang Pekanbaru. Metode pengumpulan data langsung dengan pihak berwenang dalam memberikan informasi perusahaan melalui wawancara. Hasil penelitian menunjukkan bahwa ada beberapa perbedaan dalam sistem pembiayaan KPR antara Bank Syariah Mandiri dengan BMT "X" cabang Pekanbaru. Diantaranya adalah perbedaan dalam penentuan margin, perhitungan angsuran, angsuran default (macet) dan mark-up margin.
\end{abstract}

Kata Kunci : Pembiayaan, Murabahah, Bank Syariah, BMT.

\section{ABSTRACT}

The purpose of the research investigates the differences in the financing system between Bank Syariah Mandiri (BSM) and BMT " $X$ " in Pekanbaru. The samples in this research are Bank Syariah Mandiri and BMT " $X$ " in Pekanbaru. The method of collecting data directly with the authorities in providing company information using data collection techniques with Interview. The results showed that there were several differences in the mortgage financing system between Bank Syariah Mandiri and BMT " $X$ " Pekanbaru. There are margins, how to calculate installments, default installments and margin mark-up.

Keywords : Financing, Murabahah, Islamic Bank, BMT. 


\section{PENDAHULUAN}

Produk KPR yang ada pada perbankan syariah pada dasarnya berbeda dengan KPR yang ada di perbankan konvensional. Perbedaan ini dapat terjadi karena terdapat perbedaan prinsip antara perbankan syariah dengan perbankan konvensional. Dalam perbankan syariah biasa dikenal konsep berbasis bagi hasil dan juga perdagangan. Sedangkan dalam perbankan konvensional dikenal sistem yang berbasis bunga. Dalam produk yang biasa dikenal dengan nama KPR Syariah ini terdapat beberapa karakteristik yang berbeda, diantaranya adalah tidak adanya pemberlakuan sistem kredit yang ada pada perbankan konvensional. Sementara pada perbankan syariah dikenal sistem murabahah yang berbasis margin. Sebagian besar metode dengan akad murabahah digunakan sebagai pembiayaan di perbankan syariah maupun pada koperasi syariah lainnya seperti Baitul Mall Wat Tamwil (BMT). Meskipun demikian, secara prinsip murabahah sangat jauh berbeda dengan suku bunga dalam perbankan konvensional. Murabahah adalah penjualan barang oleh seseorang kepada pihak lain dengan pengaturan bahwa penjual berkewajiban untuk mengungkapkan kepada pembeli harga pokok dari barang dan margin keuntungan yang dimasukkan kedalam harga jual barang tersebut. Pembiayaan dapat secara tunai atau tangguhan. Jika ditinjau dari segi definisi, maka murabahah dapat dipahami sebagai keuntungan yang disepakati.

Bank Syariah Mandiri dan BMT " $X$ " memberikan produk pembiyaan hunian syari'ah dalam bentuk pembayaran secara kredit atau angsuran yang memiliki beberapa sistem, prosedur dan persyaratan yang harus dipenuhi bagi calon penerima pembiayaan.

Untuk mengetahui jumlah nasabah yang menggunakan akad murabahah pada Bank Syariah Mandiri dan BMT "X" Cabang Pekanbaru tahun 2017 maka dapat dilihat pada tabel berikut ini :

Tabel 1. Perkembangan Jumlah Nasabah Dalam Pembiayaan Hunian Syariah Akad Murabahah pada Bank Syariah Mandiri dan BMT "X" Cabang Pekanbaru

\begin{tabular}{ccc}
\hline \multirow{2}{*}{ Tahun } & \multicolumn{2}{c}{ Pembiayaan Hunian Syariah } \\
\cline { 2 - 3 } & Bank Syariah Mandiri & BMT "X" \\
\hline 2017 & 34 & 30 \\
\hline Sumber : Bank Syariah Mandiri dan BMT "X” Cabang Pekanbaru (2017)
\end{tabular}

Berdasarkan dari tabel diatas dapat diketahui jumlah nasabah yang melakukan pembiayaan hunian syariah dengan akad murabahah pada tahun 2017 pada Bank Syariah Mandiri lebih banyak dibandingkan dengan BMT " $X$ " cabang Pekanbaru. Pada tahun 2017 pembiayaan hunian syariah dengan akad murabahah sebanyak 34 nasabah pada Bank Syariah Mandiri. Sedangkan pembiayaan hunian syariah dengan akad murabahah pada BMT "X" sebanyak 30 nasabah.

Penelitian mengenai kajian masalah penyaluran pinjaman pernah dilakukan oleh Rahman dan Shahimi, S. (2010), Louzis et al.
(2012), Thalassinos et al. (2015), Salas dan Saurina (2002), Jimenez dan Saurina (2006), Das dan Ghosh (2007), Boudriga et al. (2009), Bonfim (2009) Rinaldi dan Sanchis-Arellano (2006), Castro (2012), Berger dan De Young, (1997), Ahmad dan Arif (2007), Thalassinos et al. (2012), haryono et al. (2016), Setyawati et al. (2017), Effendi dan Yuniarti (2018), namun sangat terbatas penelitian mengenai perbedaan pembiayaan antara bank syariah sehingga dapat diketahui terdapat perbedaan sistem pembiayaan yang dilakukan oleh bank syariah. Dalam penelitian ini bertujuan menginvestigasi perbedaan sistem pembiayaan 
antara Bank Syariah Mandiri dengan BMT "X" di Pekanbaru.

\section{TINJAUAN PUSTAKA \\ Pengertian Akad Murabahah}

$B a$ 'i al-murabahah adalah jual beli barang pada harga asal dengan tambahan keuntungan yang di sepakati. Dalam bai al-murabahah, penjual harus memberitahu harga produk yang ia beli dan menentukan suatu tingkat keuntungan sebagai tambahannya. Misalnya, pedagang eceran membeli komputer dari grosir dengan harga Rp. 10,000,000 Kemudian ia menambahkan keuntungan sebesar Rp. 750,000 dan ia menjual kepada si pembeli dengan harga Rp. 10,750,000. Pada umumnya, si pedagang eceran tidak akan memesan dari grosir sebelum ada pesanan dari calon pembeli dan mereka sudah menyepakati tentang lama pembiayaan, besar keuntungan yang akan di ambil pedagang eceran, serta besarnya angsuran kalau memang akan di bayar secara angsuran. (Antonio, 2001)

\section{Fatwa DSN Akad Murabahah}

Pembiayaan murabahah telah diatur dalam Fatwa DSN No. 04/DSNMUI/IV/2000. Dalam fatwa tersebut disebutkan ketentuan umum mengenai murabahah, yaitu sebagai berikut:

1. Bank dan nasabah harus melakukan akad murabahah yang bebas riba.

2. Barang yang diperjual belikan tidak diharamkan oleh syarie at Islam

3. Bank membiayai sebagian atau seluruh harga pembelian barang yang telah disepakati kualifikasinya.

4. Bank membeli barang yang diperlukan nasabah atas nama bank sendiri, dan pembelian ini harus sah dan bebas riba.

5. Bank harus menyampaikan semua hal yang berkaitan dengan pembelian, misalnya jika pembelian dilakukan secara utang. Bank kemudian menjual barang tersebut kepada nasabah (pemesan) dengan harga jual senilai harga plus keuntungannya. Dalam kaitan ini bank harus memberitahu secara jujur harga pokok barang kepada nasabah berikut biaya yang diperlukan.

6. Nasabah membayar harga barang yang telah disepakati tersebut pada jangka waktu tertentu yang telah disepakati.

7. Untuk mencegah terjadinya penyalahgunaan atau kerusakan akad tersebut, pihak bank dapat mengadakan perjanjian khusus dengan nasabah.

8. Jika bank hendak mewakilkan kepada nasabah untuk membeli barang kepada pihak ketiga, akad jual beli murabahah harus dilakukan setelah barang, secara prinsip menjadi milik bank.

Aturan yang dikenakan kepada nasabah dalam murabahah ini dalam fatwa adalah sebagai berikut:

1. Nasabah mengajukan permohonan dan perjanjian pembelian suatu barang atau asset kepada bank.

2. Jika bank menerima permohonan tersebut ia harus membeli terlebih dahulu asset yang dipesannya secara sah dengan pedagang.

3. Bank kemudian menawarkan asset tersebut kepada nasabah dan nasabah harus menerima (membeli)-nya sesuai dengan perjanjian yang telah disepakatinya, harus membuat kontrak jual beli.

4. Dalam jual beli ini bank dibolehkan meminta nasabah untuk membayar uang muka saat menandatangani kesepakatan awal pemesanan.

5. Jika nasabah kemudian menolak membeli barang tersebut, biaya riil bank harus dibayar dari uang muka tersebut.

6. Jika nilai uang muka kurang dari kerugian yang harus ditanggung oleh bank, bank dapat meminta kembali sisa kerugiannya kepada nasabah. 
7. Jika uang muka memakai kontrak urbun sebagai alternatif dari uang muka, maka: (1) jika nasabah memutuskan untuk membeli barang tersebut, ia tinggal membayar sisa harga; atau (2) jika nasabah batal membeli, uang muka menjadi milik bank maksimal sebesar kerugian yang ditanggung oleh bank akibat pembatalan tersebut; dan jika uang muka tidak mencukupi, nasabah wajib melunasi kekurangannya.

Skema Akad Murabahah di Perbankan Syariah

Secara umum, aplikasi perbankan dengan akad murabahah dapat digambarkaan dengan skema sebagai berikut:

Gambar 1. Skema Kerja dalam Akad Murabahah

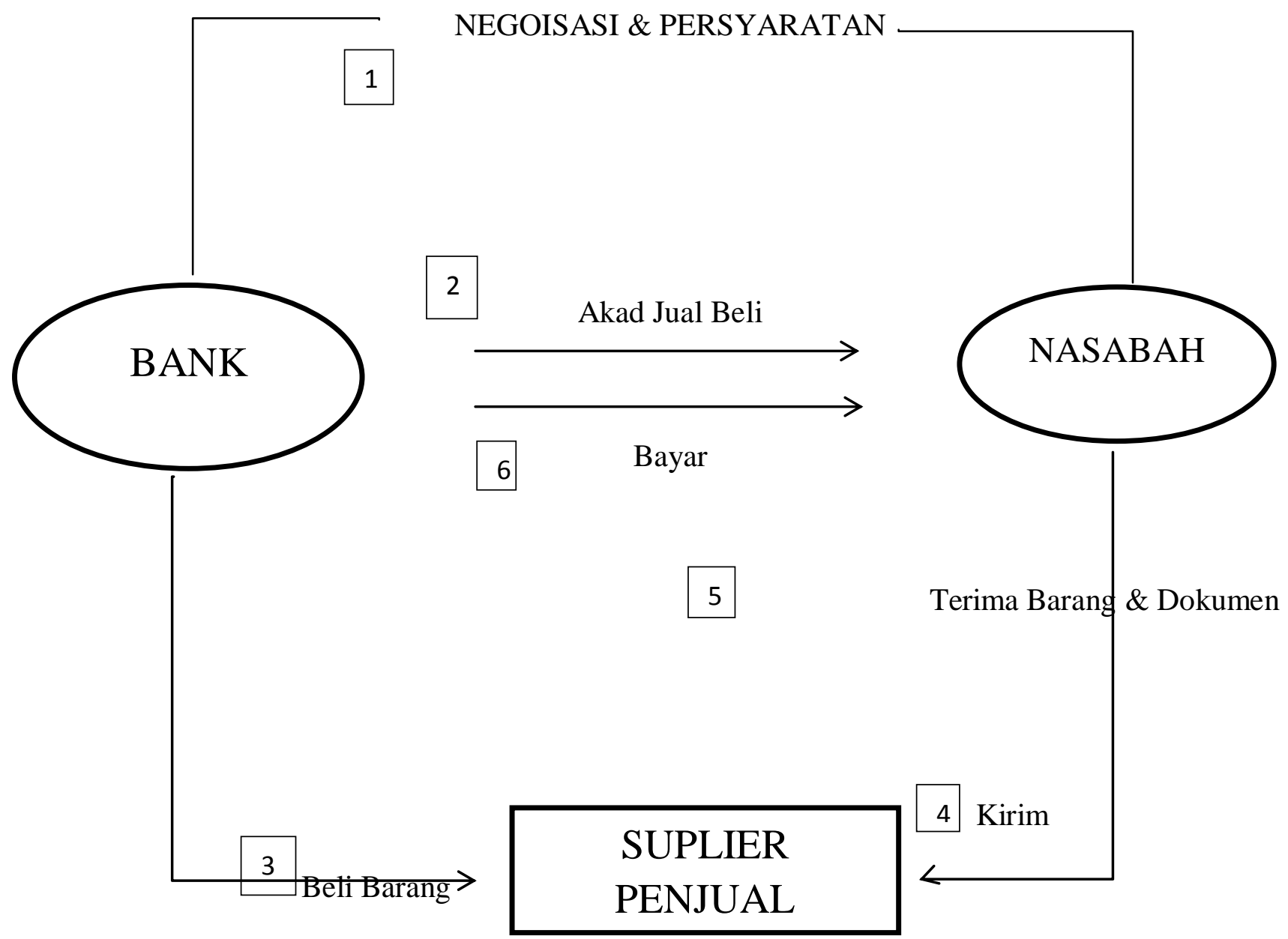

Sumber : Kuncoro (2005)

\section{METODE PENELITIAN}

Lokasi penelitian ini pada Bank Syariah Mandiri Cabang Pekanbaru di jalan Jendral Sudirman No. 410 dan Koperasi BMT "X" cabang Pekanbaru Riau. Adapun penulis memilih lokasi ini karena adanya produk yang ditawarkan oleh bank tersebut yaitu hunian syariah atau KPR syariah.

Jenis dan sumber data yang digunakan dalam penelitian ini adalah:

a) Data Primer yaitu, data yang langsung diperoleh dari objek yang diteliti yang berkaitan dengan masalah yang diteliti. 
Dalam hal ini data diperoleh langsung dari marketing Bank Syariah Mandiri dan Koperasi BMT "X" Cabang Pekanbaru.

b) Data sekunder, diperoleh dari sumber penelitian dengan mempelajari referensi yang memiliki hubungan dengan sasaran penelitian. Baik dari buku, skripsi terdahulu, brosur, dan situs internet untuk mendukung penelitian ini.

Populasi dalam peneltian ini adalah Bank Syariah Mandiri dan Koperasi BMT "X"
Cabang Pekanbaru sedangkan yang menjadi sampel adalah nasabah yang menggunakan KPR dengan Akad Murabahah. Metode pengumpulan data langsung dengan pihakpihak yang berwenang dalam memberikan informasi perusahaan dengan menggunakan teknik pengumpulan data dengan interview, yaitu wawancara langsung dengan pihak marketing di Bank Syariah Mandiri dan BMT "X" cabang Pekanbaru.

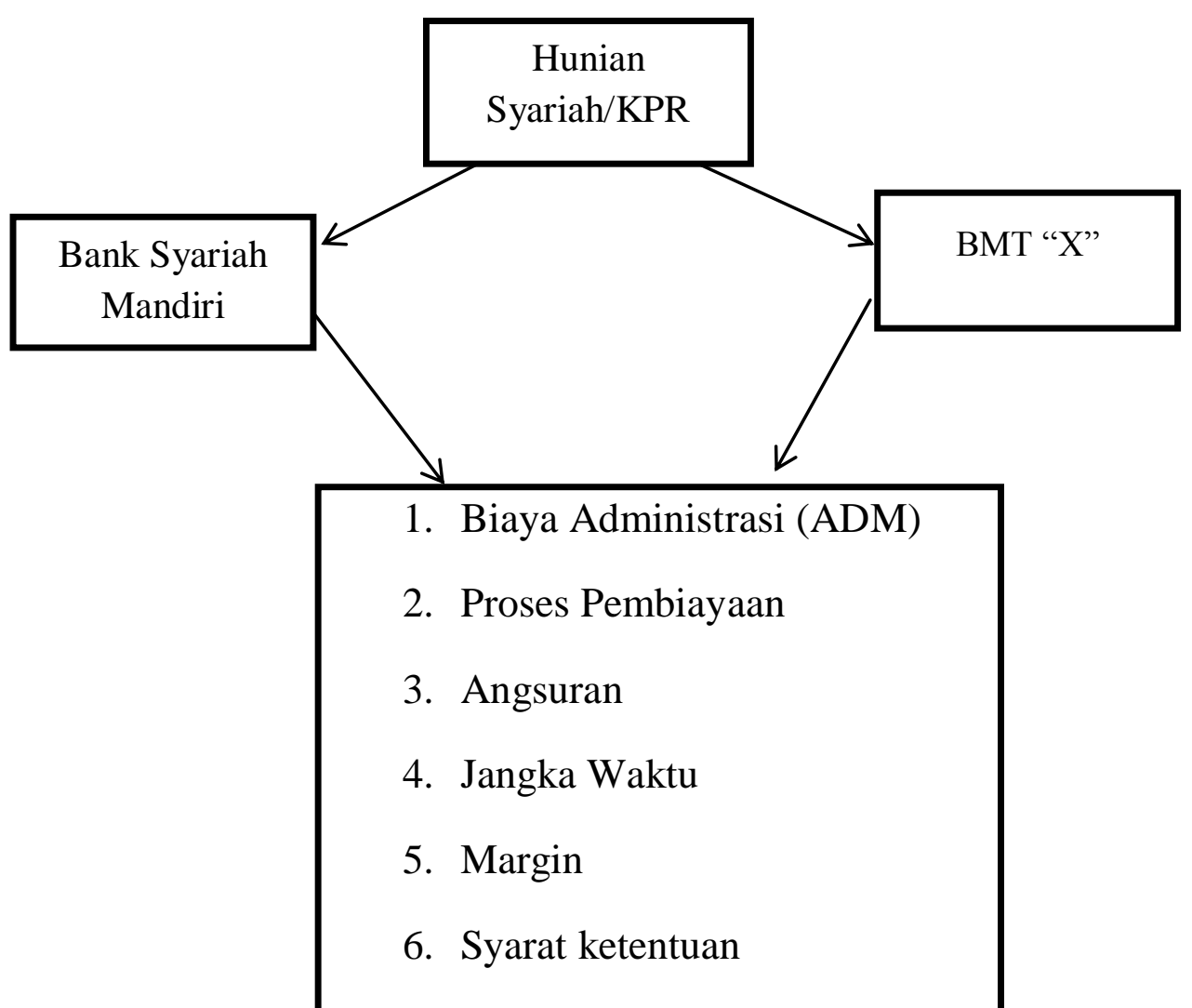

Gambar 2. Kerangka Berpikir

HASIL DAN PEMBAHASAN

\section{Deskripsi Data}

Biaya Administrasi (ADM)

Adapun biaya ADM pada Bank dan BMT berbeda yaitu:

- Bank Syariah Mandiri :

Biaya $\mathrm{ADM}=1 \% \mathrm{x}$ Harga Plafond
Contoh :

Jika biaya plafond sebesar Rp.150.000.000,maka adapun perhitungan nya Biaya $\mathrm{ADM}=1 \%$ x Rp. $150.000 .000,-=\mathrm{Rp}$. 1.500.000,-

- BMT "X" :

Biaya ADM tidak ada melainkan jika kita ingin melakukan pembiayaan KPR kita harus 
menjadi anggota. Biaya yang di keluarkan adalah sebagai berikut:

$\begin{array}{ll}>\text { Simpanan Pokok } & =\text { Rp.50.000,- } \\ >\text { Simpanan Wajib } & =R p .20 .000-, \\ >\text { Simpanan Mudharabah } & =\text { Rp.10.000,- } \\ >\text { Kartu Anggota } & =\text { Rp. 5.000,- } \\ \quad \text { TOTAL } & =\text { Rp. 85.000, }\end{array}$

\section{Proses Pembiayaan}

Dari segi proses pembiayan dari pihak Bank Syariah Mandiri maupun pihak BMT "X" memiliki proses pembiayaan yang sama. Adapun hal-hal yang dilihat untuk memenuhi proses pembiayaan adalah :

\section{Karakter}

Yaitu dengan melihat karakter nasabah dengan wawancara, dan karakter nasabah dapat diketahui dengan menganalisa dari hasil pertanyaan yang dipaparkan oleh marketing bagian KPR karena bank maupun koperasi harus selektif dalam profil calon nasabah KPR tersebut. Apabila terjadi kesalahan pihak bank dan koperasi dalam menilai karakter calon nasabah KPR maka berakibat keraguan dari pihak bank dan koperasi dan mengurangi kelancaran proses pembiayaan.

2. Kapasitas

Kapasitas disini adalah kemampuan sumber penghasilan calon nasabah membiayai seluruh pengeluaran bulanan nya. Dimana cash ratio nya harus jelas, adapun cash ratio yang dimaksud adalah perbandingan antara total pendapatan per bulan dikurangi biaya-biaya bulanan dan kewajibankewajiban perbulannya dengan angsuran bulanan.

3. Jaminan

Jaminan/agunan adalah asset nasabah yang dijanjikan kepada bank jika nasabah tidak dapat mengangsur pembiayaan. Jaminan yang dimaksud harus bisa mengcover resiko pembiayaan nasabah. Objek pembiayaan wajib di jadikan jaminan/agunan. Karena untuk menghindari bank dari pengganti kerugian. Jaminan tersebut untuk berjaga-jaga agar nasabah tidak main-main dalam angsuran pembiayaan KPR ini.

4. Persetujuan Pembiayaan

Pada proses ini ditentukan apakah pembiayaan yang diajukan oleh nasabah disetujui atau tidak, karena proses ini tergantung pada kebijakan bank atau koperasi. Apabila pihak bank dan koperasi setuju, maka akan dibuatkan surat persetujuan pembiayaan, dan jika tidak disetujui maka akan dibuatkan surat penolakan pembiayaan.

5. Pengikatan

Setelah melakukan akad pembiayaan maka bank dan nasabah harus melakukan pengikatan, baik pengikatan jaminan nasabah ataupun pengikatan pembiayaan. Proses pengikatan ini melibatkan notaris, dihadiri oleh nasabah, relationship manager (bank) atau kabag Pembiayaan (BMT "X”) dan staff lainnya.

6. Pencairan

Dari sisi pengikatan pencairan sudah selesai kemudian dilakukan proses pencairan. Sebelum proses pencairan dilakukan sebelumnya dilakukan pemeriksaan terlebih dahulu terhadap semua kelengkapan yang harus dipenuhi sesuai disposisi komite proposal pembiayaan.

Pada Bank Syariah Mandiri menyerahkan uang muka/DP sebesar 30\%.

Contoh :

Jika harga rumah sebesar Rp.150.000.000,maka DP nya adalah $30 \%$ perhitungannya adalah Rp.150.000.000 x 30\% = Rp. 45.000.000,-

Sedangkan pada BMT "X" ada menggunakan DP \& Non DP. Adapun DP yang di tawarkan sebesar 30\%, jika menggunakan Non DP BMT "X" memberikan $70 \%$ dari harga rumah yang di berikan dengan syarat ada jaminan yang di miliki oleh sekandung (misalnya: ayah sekandung, ibu sekandung, anak sekandung). 
Contoh :

Perhitungan dengan menggunakan DP : Harga rumah Rp.120.000.000,- , DP sebesar $30 \%$ maka perhitungannya adalah Rp.120.000.000,- x 30\% = Rp.36.000.000,Perhitungan dengan menggunakan Non DP : DP yang diberikan $70 \%$ dari harga rumah yang di inginkan,

Contoh :

Harga rumah Rp.120.000.000,- maka pihak BMT memberikan $70 \%$ dari harga rumah perhitungan nya adalah :

Rp.120.000.000,- x $70 \%$ = Rp.84.000.000,-

Angsuran

Angsuran adalah pembayaran cicilan dengan uang tunai sebagai pembayaran angsuran yang besarnya telah ditentukan sebelumnya atau ditentukan besar kecilnya yang tergantung pada lamanya jangka waktu angsuran, yang biasanya dipakai untuk mengangsur utang. Angsuran ini telah sah jika kedua belah pihak mensepakati akad yang di berikan dan besar pembayarannya setiap bulan. Angsuran yang dimiliki Bank Syariah Mandiri berbeda dengan BMT " $\mathrm{X}$ ", adapun perbedaannya adalah :

- Bank Syariah Mandiri

Angsuran yang harus dibayar oleh calon nasabah KPR dapat dilihat pada tabel berikut ini :

Tabel 2. Tabel Angsuran Pembiayaan Hunian Syariah Dengan Akad Murabahah

\begin{tabular}{ccccc}
\hline Nominal & Tahun & Bulan & Flate Rate & Angsuran \\
\hline Rp. 150,000,000 & 9 & 108 & $7.97 \%$ & $\mathbf{2 , 3 8 4 , 6 4 2}$ \\
\hline \multicolumn{4}{c}{ Sumber : Bank Syariah Mandiri $(2017)$}
\end{tabular}

Pada Bank Syariah Mandiri angsuran pokok dan angsuran marginnya ditentukan oleh sistem yang telah ditentukan. Saat wawancara dengan Okky (marketing BSM ) dia menjelaskan bahwa "perhitungan angsuran pokok dan angsuran marginnya ditentukan dengan teknologi yang canggih Bank Syariah Mandiri menggunakan Aplikasi Kalkulator Kredit IQ yang dapat di akses di handphone". Disitu kita bisa melihat berapa besar angsuran pokok dan angsuran marginnya sesuai harga plafond yang kita inginkan. Sehingga lebih memudahkan pihak BSM dan Calon Nasabah KPR untuk mengetahui angsuran yang harus dibayar.

- BMT "X"

Angsuran yang dimiliki BMT ini sendiri berbeda dengan Bank Syariah Mandiri. Disini di memakai margin flat yaitu sama sampai pembayaran selesai.

Contoh :

Pak Amir ingin melakukan KPR selama 9 tahun/108 bulan dengan harga rumah Rp.150.000.000,-.Margin yang telah di tetapkan BMT "X" sebesar 0,7\%.

Cara perhitungannya :

Biaya pokok:

Rp.150.000.000,- / 108 bulan = Rp. 1.388.888,889 atau Rp.1.390.000,-

Biaya margin :

Rp.150.000.000 x 0,7\% = Rp.1.050.000,Jadi total pembiayaan perbulan yang harus di bayar Pak Amir setiap bulan selama 9 tahun atau 108 bulan adalah sebesar:

Rp.1.390.000,- + Rp.1.050.000,- = Rp.2.440.000, 
Tabel 3. Tabel Pembiayaan KPR Dengan Akad Murabahah ( Plafond Rp. 150.000.000,- )

\begin{tabular}{|c|c|c|c|}
\hline \multirow{2}{*}{ Plafond } & \multicolumn{3}{|c|}{ Jangka Waktu selama 108 bulan ( 9 tahun ) } \\
\hline & Angsuran pokok & Angsuran Margin & Total Angsuran $(\mathrm{P}+\mathrm{M})$ \\
\hline Rp.150.000.00,- & Rp.1.390.000,- & Rp.1.050.000,- & Rp.2.440.000,- \\
\hline
\end{tabular}

Sumber : BMT “X” Cabang Pekanbaru (2017)

\section{Jangka Waktu}

Jangka waktu yang di berikan pada BSM dan BMT berbeda. Jika pada BSM jangka waktu yang diberikan selama 15 Tahun sedangkan pada BMT "X" selama 10 tahun.

\section{Penetapan Margin}

Penetapan margin pada Bank Syariah Mandiri di tetapkan oleh ALCO (Asset Liability Committee). ALCO memiliki wewenang membuat keputusan dan mengatur asset dan jaminan. Strategi harga atas pinjaman (pembiayaan), membangun praktek penguasaaan dana-dana dan pilihan untuk alokasi pinjaman (pembiayaan), serta menyusun action plan berdasarkan sebab berlakunya variasi.

Antonio (2001) menjelaskan bahwa tanggung jawab ALCO adalah mengelola posisi dan alokasi dana-dana bank agar tersedia likuiditas yang cukup. Memaksimalkan keuangan dan meminimalkan resiko yang mungkin terjadi.

Setelah Bank Syariah mendapatkan referensi margin keuntungan dari rapat Tim ALCO ini, maka bank melakukan penerapan harga jual.

Adapun penetapan marginnya :

- Tahun 1-5 = 12,25\%

- Tahun 6-10=13,25\%

- Tahun $11-15=14,25 \%$

Contoh :

Sedangkan di BMT "X" itu sendiri penetapan margin dari perhitungan koperasi itu sendiri. Marginnya sebesar $0,7 \%$ dari perhitungan BMT "X"
Contoh :

Harga rumah Rp.100.000.000,- margin yang di tetapkan adalah $0,7 \%$ x Rp.100.000.000,- = Rp.700.000,-

\section{Syarat ketentuan}

Syarat ketentuan harus di penuhi oleh calon nasabah KPR agar bisa melakukan tahap selanjutnya. Jika pada BSM syarat ketentuannya yang harus dipenuhi adalah :

1. Fotokopi KTP suami/ Istri

2. Fotokopi Kartu Keluarga

3. Fotokopi Surat Nikah

4. Fotokopi NPWP dan SPT tahunan

5. Fotokopi Rekening Bank 3 bulan Terakhir

6. SK Pengangkatan atau Surat Ket. Bekerja / Surat Izin Praktek

7. Slip Gaji Bulanan 3 Terakhir (Asli) atau surat ket penghasilan

8. Fotokopi Sertfikat agunan, IMB dan PBB

Biaya - Biaya:

1. Biaya ADM $1 \%$ dari Plafond

2. Asuransi Jiwa

3. Asuransi Kebakaran

4. Biaya Notaris

5. Materai 20 lembar

Pada BMT syarat ketentuan yang harus di penuhi adalah :

$>$ Fotokopi KTP Pemohon

$>$ Fotokopi KTP Suami / Istri Pemohon

$>$ Fotokopi KK / Surat Nikah

$>$ Fotokopi Rekening Listrik

$>$ Slip Gaji / Surat Ket. Penghasilan

$>$ Surat pernyataan jaminan ( form dari BMT )

Fotokopi Jaminan 
Usia anggota max 60 tahun

$>$ Pembiayaan di asuransikan (asuransi jiwa syariah)

Jaminan :

Pembiayaan $<=$ Rp. 5.000.000,-

BPKP kendaraan roda dua (5 tahun terakhir)

$>$ Pembiayaan > Rp. 5.000.000,-

Sertifikat, SKGR Camat, BKPK mobil.

\section{Konsekuensi Hukum Jika Nasabah} Wanprestasi

Dalam pembiayaan Murabahah, apabila nasabah telah melakukan kelalaian pembayaran angsuran bulanan kepada Bank, maka akan dilakukan tahapan tahapan sebagai berikut :

- Nasabah akan di panggil dan dilakukan mediasi antara pihak Bank dengan nasabah.

- Apabila nasabah hilang tanpa kabar selama 2-3 bulan, maka pihak Bank akan mengirimi surat pemberitahuan.

- Apabila setelah 2-3 bulan nasabah masih belum memberi kabar dan belum melakukan angsuran bulanan kepada Bank maka ditunggu sampai 2 minggu, jika 2 minggu juga tidak ada balasan dari nasabah maka dikirimi lagi surat pembeitahuan kedua.

- Tahapan terakhir jika nasabah juga tidak ada kabar maka jaminan asuransi nya di lelang pada pihak Bank.

Sedangkan di BMT " $X$ " tahapan yang dilakukan jika nasabah lalai dalam pembiayaan tersebut adalah :

- Nasabah akan di panggil untuk melakukan mediasi pada pihak BMT.

- Apabila nasabah tak juga lancar dalam pembiayaan maka pihak BMT akan memberikan surat panggilan sebanyak $3 x$.

- Jika nasabah juga tak ada kabar maka pihak BMT melakukan eksekusi jaminan.

Perbandingan Pembiayaan Hunian Syariah dengan Akad Murabahah Pada Bank Syariah Mandiri dan BMT "X" Cabang Pekanbaru dapat dilihat pada Tabel berikut:

\section{Tabel 4. Klarifikasi Perbandingan Pembiayaan}

\begin{tabular}{|c|c|c|c|}
\hline \multirow[b]{2}{*}{ No } & \multirow[b]{2}{*}{ Keterangan } & \multicolumn{2}{|c|}{ Pembiayaan KPR dengan Akad Murabahah } \\
\hline & & Bank Syariah Mandiri & BMT “X” \\
\hline 1. & Administrasi & Biaya $=1 \%$ dari Plafond & Biaya menjadi anggota $=$ Rp.85.000,- \\
\hline 2. & DP / uang muka & Sebesar $30 \%$ dari plafond & $\begin{array}{l}\text { - } \text { Dp } 30 \% \text { dari plafond } \\
\text { Non DP (menyerahkan } \\
\text { jaminan sebesar } 70 \% \text { dari } \\
\text { harga plafond dan syarat } \\
\text { tertentu). }\end{array}$ \\
\hline 3. & Jangka Waktu & 15 Tahun & 10 Tahun \\
\hline 4. & Margin & $\begin{array}{ll}- & \text { Tahun } 1-5=12,25 \% \\
\text { - } & \text { Tahun } 6-10=13,25 \% \\
\text { - } & \text { Tahun } 11-15=14,25 \%\end{array}$ & Sebesar $0,7 \%$ dari perhitungan BMT. \\
\hline 5. & Plafond Maksimum & Rp. 1.000.000.000,- & Rp. 1.200.000.000,- \\
\hline 6. & Angsuran & Ditentukan oleh sistem yang di & Adanya rumus untuk menghitung \\
\hline
\end{tabular}




\begin{tabular}{|c|c|c|c|}
\hline & & pakai oleh BSM. & angsuran pokok dan angsuran margin \\
\hline 7. & Objek Pembiayaan & Rumah, Kios, Apartement, Ruko. & Rumah, Kios, Apartement, Ruko. \\
\hline
\end{tabular}

\section{KESIMPULAN}

Terdapat beberapa persamaan dan perbedaan dalam sistem pembiayaan KPR antara Bank Syariah Mandiri dan BMT "X" Cabang Pekanbaru. Terdapat perbedaan dalam penetapan margin, yaitu pada BSM penetapan margin ditentukan pada ALCO, sedangkan penetapan margin pada BMT ditentukan oleh BMT itu sendiri.

Adanya perbedaan cara perhitungan angsurannya, jika pada BSM besar angsurannya ditentukan oleh aplikasi yang digunakan sedangkan pada BMT ditentukan secara manual oleh rumus yang ditentukan oleh BMT "X". Adanya perbedaan biaya ADM, yaitu pada BSM biaya ADM $1 \%$ dari harga plafond sedangkan pada BMT biaya ADM nya sebesar Rp.85.000,-Adanya sedikit perbedaan pada angsuran yang macet, jika BSM melakukan tindakan surat panggilan hanya 2 kali sedangkan BMT melakukan tindakan surat panggilan sebanyak 3 kali. Disini pihak BMT lebih meringankan jika nasabah macet dalam pembiayaan. Adanya perbedaan margin, yaitu pada BSM marginnya dari tahun $1-5$ sebesar $12,25 \%$, tahun 6-10 sebesar $13.25 \%$, dan tahun 11-15 sebesar $14,25 \%$ sedangkan pada BMT marginnya adalah sebesar $0,7 \%$ perhitungan BMT.

\section{DAFTAR PUSTAKA}

Antonio, Muhammad Syafii. 2001. Bank Syariah dari Teori ke Praktik. Gema Insani. Jakarta.

Berger, Allen, N. DeYoung, R. 1997. Problem Loans and Cost Efficiency in Commercial Banks. Journal of Banking \& Finance. Vol. 21, Issue 6.

Bonfim, D. 2009. Credit Risk Drivers: Evaluating the Contribution of Firm Level Information and of
Macroeconomic Dynamics. Journal of Banking \& Finance. Vol. 33, Issue 2.

Boudriga, A., Taktak, N.B. and Jellouli, S. 2009. Banking Supervision and Non-performing Loans: A CrossCountry Analysis. Journal of Financial Economic Policy. Vol. 1, No. 4.

Castro, V. 2012. Macroeconomic Determinants of the Credit Risk in the Banking System: The Case of the GIPSI. NIPE Working Paper. Boston University.

Das, A. and Ghosh, S. 2007. Determinants of Credit Risk in Indian State-Owned Banks: An Empirical Investigation. Economic Issues. Vol. 12, No. 2.

Effendi, K.A. and Yuniarti, R.D. 2018. Credit risk and macroeconomics of Islamic Banking in Indonesia. Journal of Accounting, Finance and Auditing Studies. Vol. 4, Issue 2.

Haryono, Y., Ariffin, N.M., Hamat, M. 2016. Factors Affecting Credit Risk in Indonesian Islamic Banks. Journal of Islamic Finance. Vol. 5, N. 1, p. 12-25.

Jimenez, G. Saurina, J. 2006. Credit Cycles, Credit Risk and Prudential Regulation. International Journal of Central Banking. Vol. 2, No. 2.

Kuncoro, Mudjarat. 2005. Manajemen Bank Syariah. Ekonisia. Yogyakarta.

Louzis, D.P., Vouldis, A.T., Metaxas, V.L. 2012. Macroeconomic and Bank Specific Determinants of NonPerforming Loans in Greece: A Comparative Study of Mortgage, Business and Consumer Loan Portfolios. Journal of Banking \& Finance. Vol. 36, Issue 4. 
Rahman, A.A., Shahimi, S. 2010. Credit risk and Financing Structure of Malaysian Islamic Banks. Journal of Economic Cooperation and Development. Vol. 31, No. 3, p. 83105.

Rinaldi, L. and Sanchis-Arellano, A. 2006. Household Debt Sustainability: What Explains Household NonPerforming Loans? An Empirical Analysis. Working Paper Series 570. European Central Bank.

Salas, V. and Saurina, J. 2002. Credit Risk in Two Institutional Regimes: Spanish Commercial and Savings Banks. Journal of Financial Services Research. Vol. 22, Issue 3, p. 203224.

Setyawati, I., Suroso, S., Suryanto, T., Nurjannah, S.D. 2017. Does Financial Performance of Islamic Banking is better? Panel Data Estimation. European Research Studies, Vol. 20, Issue 2A, p. 592606.

Thalassinos, I.E., Hanias, P.M. and Curtis, G.P. 2012.Time series prediction with neural networks for the Athens Stock Exchange indicator. European Research Studies. Vol. $\mathrm{XV}$, Issue 2.

Thalassinos, I.E., Stamatopoulos, D.T. and Thalassinos, E.P. 2015. The European Sovereign Debt Crisis and the Role of Credit Swaps. In The WSPC Handbook of Futures Markets (Memory of late of Milton Miller (Nobel 1990) World Scientific Handbook in Financial Economies Series), eds W. T. Ziemba and A.G. Malliaris, pp. 605639, Vol. 5, Chapter 20, World Scientific Publising. Singapore 